\title{
Relationship between Plasticizer Content and Tensile Bond Strength of Soft Denture Liners to a Denture Base Resin
}

\author{
Guang HONG, Hiroshi MURATA and Taizo HAMADA \\ Department of Prosthetic Dentistry, Graduate School of Biomedical Sciences, Hiroshima University, 1-2-3 Kasumi, Minami- \\ ku, Hiroshima, 734-8553, Japan \\ Corresponding author, E-mail:hong@hiroshima-u.ac.jp
}

Received November 28, 2003/Accepted March 19, 2004

\begin{abstract}
The purpose of this study was to determine the influence of plasticizer content on the tensile bond strength of heat-cured acrylic soft denture liners to a denture base resin. Differences among materials were significant, except for $100 \mathrm{wt} \%$ Dibutyl Sebacate (DBS) and $80 \mathrm{wt} \%$ DBS of tensile bond strength. The bond strength of all materials to the denture base increased with an increase in thermal cycles significantly except for $40 \mathrm{wt} \%$ DBS. The tensile bond strength of soft denture liners to the denture base resin significantly decreased with an increase of plasticizer contents. Differences were found among the difference plasticizer contents in failure types between the denture base resin and soft denture liners. The results suggest that the tensile bond strengths of heat-cured acrylic soft denture liners to the denture base resin were lower with an increase in plasticizer content.
\end{abstract}

Key words: Soft denture liner, Tensile bond strength, Plasticizer

\section{INTRODUCTION}

Excessive absorption of the alveolar bone and lesion of the alveolar mucosa are often observed in patients who have worn the complete dentures for a long time. Soft denture liners have been used in these patients because of their viscoelastic properties. These materials are also useful when the oral mucosa covering the denture bearing area is of inadequate thickness ${ }^{1,2)}$. In the clinic, the silicone type, acrylic resin type and fluoroethylene type were often used for soft denture liners ${ }^{3,4)}$.

Murata et $a l^{5)}$ reported acrylic soft denture liners indicated the most marked improvement in masticatory function because they exhibited viscoelastic properties. Furthermore, it is reported that the bond strength of heat-cured acrylic soft denture liners to the denture base resin is stronger than the other types of material ${ }^{6-8)}$.

The loss of bond of a soft denture liner to a denture base resin is a common cause of failure in denture lining ${ }^{9-11)}$. Bond strength is one of the most important factors which decide the use period of the soft denture liner as well as the material's own durability. Several tests have been used to assess the bond strength of soft denture liners. Wright ${ }^{12)}$ estimated the bond strength of nine resilient denture liners using a peeling test. Kulak-Ozkan et al. ${ }^{13)}$ assessed the bond strength of six silicone based soft denture liners using a tensile test. Al-Athel and Jagger ${ }^{14)}$ measured the bond strength of silicone soft denture liners using tensile, shear and peeling tests. Although the peel test closely simulates the force applied at the interface between the soft denture liner and the denture base, direct gripping of the soft denture liner in the peel test may damage the sample integrity at the gripped region, and the force may not be applied at the interface between both materials directly because the applied force may depend on the properties of the soft denture liner. The tensile test did not simulate the clinical forces that may induce separation between the soft denture liner and the denture base resin. However, the force was applied to the bonding area of both materials. This test was effective in ranking the materials and in evaluating the failure made.

Among all types of soft denture liner, acrylic soft denture liners are constituted of a polymer, monomer and plasticizer ${ }^{15)}$. Although the bonding of different types of soft denture liners to denture bases has been widely investigated ${ }^{10,11,16-21)}$, influence of plasticizer content on bond strength of acrylic soft denture liners to a denture base resin has not been evaluated.

The purpose of this study was to determine the influence of plasticizer content on tensile bond strength of heat-cured acrylic soft denture liners to a denture base resin. In addition, the influence of the thermal cycling on their bond strength was examined.

\section{MATERIALS AND METHODS}

Table 1 gives details of the acrylic soft denture liners used in this study. Poly (ethyl methacrylate) (PEMA, Lot No. CKG; Nissin Dental Products Inc., Kyoto, Japan) with weight average molecular weight of $5.0 \times 10^{5}$ was used as powder. Methyl 
methacrylate (MMA, Lot No. FGK01; Tokyo Kasei Kogyo Co., Ltd., Tokyo, Japan) containing dibutyl sebacate (DBS, Lot No. GJ01; Tokyo Kasei Kogyo Co., Ltd., Tokyo, Japan) at 20, 40, 60 and 80 wt\%, and pure DBS were used as liquids. A catalyst was not included in the liquids. The powder liquid ratio was 1.5. Denture base acrylic resins (Acron, Lot No. Powder-030471, Liquid-0112203; P/L: 10/4.3 g; GC Corp., Tokyo, Japan) were polymerized according to the manufacturer's recommendation to the rectangular blocks $(35 \times 10 \times 10 \mathrm{~mm})$. The section surfaces of tensile test specimens were abraded with 400 grit waterproof abrasive paper, and were scrubbed with tap water for $15 \mathrm{sec}$, and allowed to air dry for at least 5 min.

Two denture base resin blocks were placed back into the metal mold with a $2 \mathrm{~mm}$-thick spacer. The dough which consisted of powders and liquids mixed for $30 \mathrm{sec}$ was then packed into the space (Fig. 1), trial packed, and processed in a water bath. Over the period of $30 \mathrm{~min}$, the temperature of the water slowly increased from cold water to boiling, and boiled for $60 \mathrm{~min}$. After polymerization, the samples were exposed to thermal cycles (TC) between 4 and $60^{\circ} \mathrm{C}$ for $1 \mathrm{~min}(0,1250,2500,5000$ and $10000 \mathrm{TC})$, and an accelerated test of deterioration was per-

Table 1 Materials used in this study

\begin{tabular}{cccc}
\hline Powder & \multicolumn{3}{c}{ PEMA[poly (ethyl methacrylate) } \\
\hline \multirow{2}{*}{ Liquid } & Code & Monomer & Plasticizer \\
\cline { 2 - 4 } & & MMA (wt\%) & DBS (wt\%) \\
\cline { 2 - 4 } & D0 & 100 & 0 \\
& D20 & 80 & 20 \\
D40 & 60 & 40 \\
& D60 & 40 & 60 \\
& D80 & 20 & 80 \\
& D100 & 0 & 100 \\
\hline
\end{tabular}

formed

Five samples of each material were placed under tension until failure using a Materials Testing $\mathrm{Ma}$ chine (Instron Corp. Model 5565, Canton, Mass.) at a crosshead speed of $20 \mathrm{~mm} / \mathrm{min}$.

The load $(\mathrm{N})$ at which failure occurred was recorded together with the type of failure. The tensile bond strengths were calculated as follows:

Tensile Bond Strength $(\mathrm{MPa})=$

Maximum load (N)/Cross-sectional area $\left(\mathrm{mm}^{2}\right)$

Mean and standard deviations were determined for all materials. The type of failure was assessed visually and recorded as being cohesive, adhesive, or mixed, depending on whether fracture surface was in the soft denture liner only, at the denture base resinsoft denture liner interface only, or in both. Complete adhesive failure was defined as $100 \%$, and complete cohesive failure was defined as $0 \%$. Thus, mixed failure was defined as the percentages of the area of the adhesive failure against the crosssectional areas.

The tensile bond strengths were analyzed by oneway analysis of variance (ANOVA) to determine significance among soft denture liners and among thermal cycles. The differences of bond strength among the materials were tested with the Tukcy's multiple comparison tests. All data were analyzed at a 0.05 level of significance.

\section{RESULTS}

The mean and standard deviation (SD) values of tensile bond strength at $0 \mathrm{TC}$ are shown in Fig. 2. D0 and D20 samples could not be measured. The grip of the materials testing machine is pneumatic type. The sample slid from the grip because the bond strength of D0 and D20 was too strong and the put

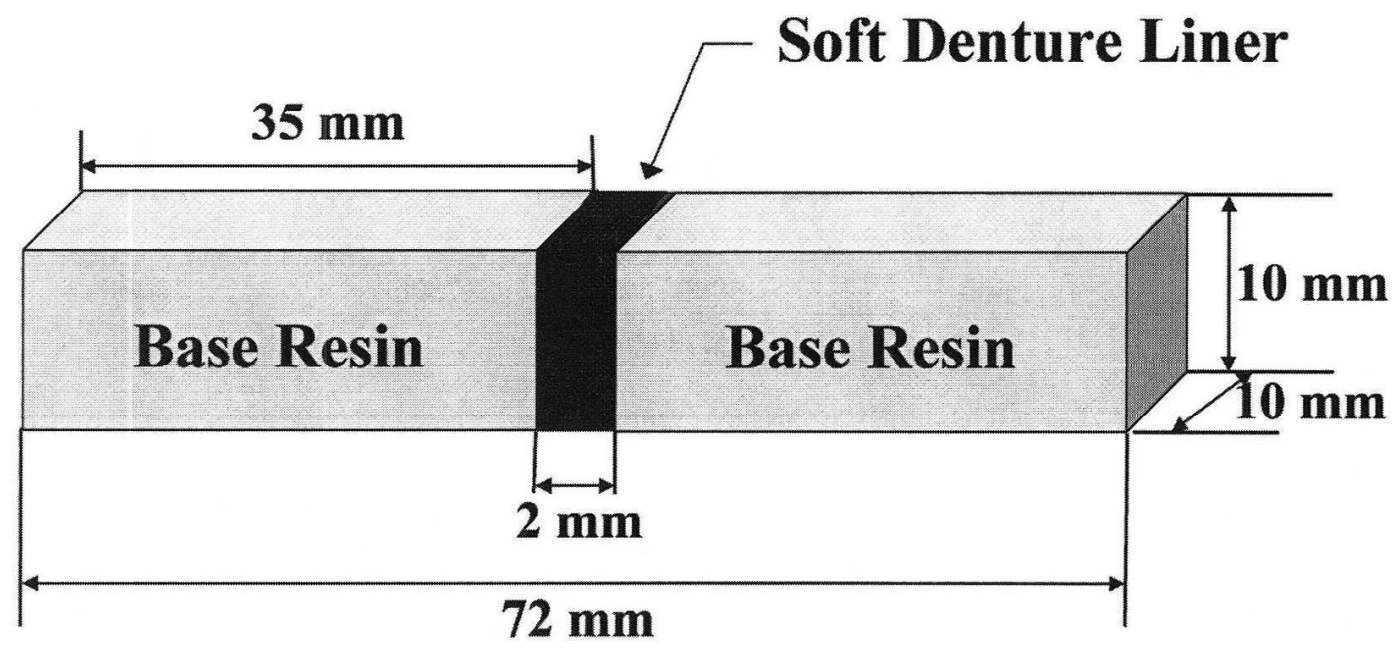

Fig. 1 Test sample. 


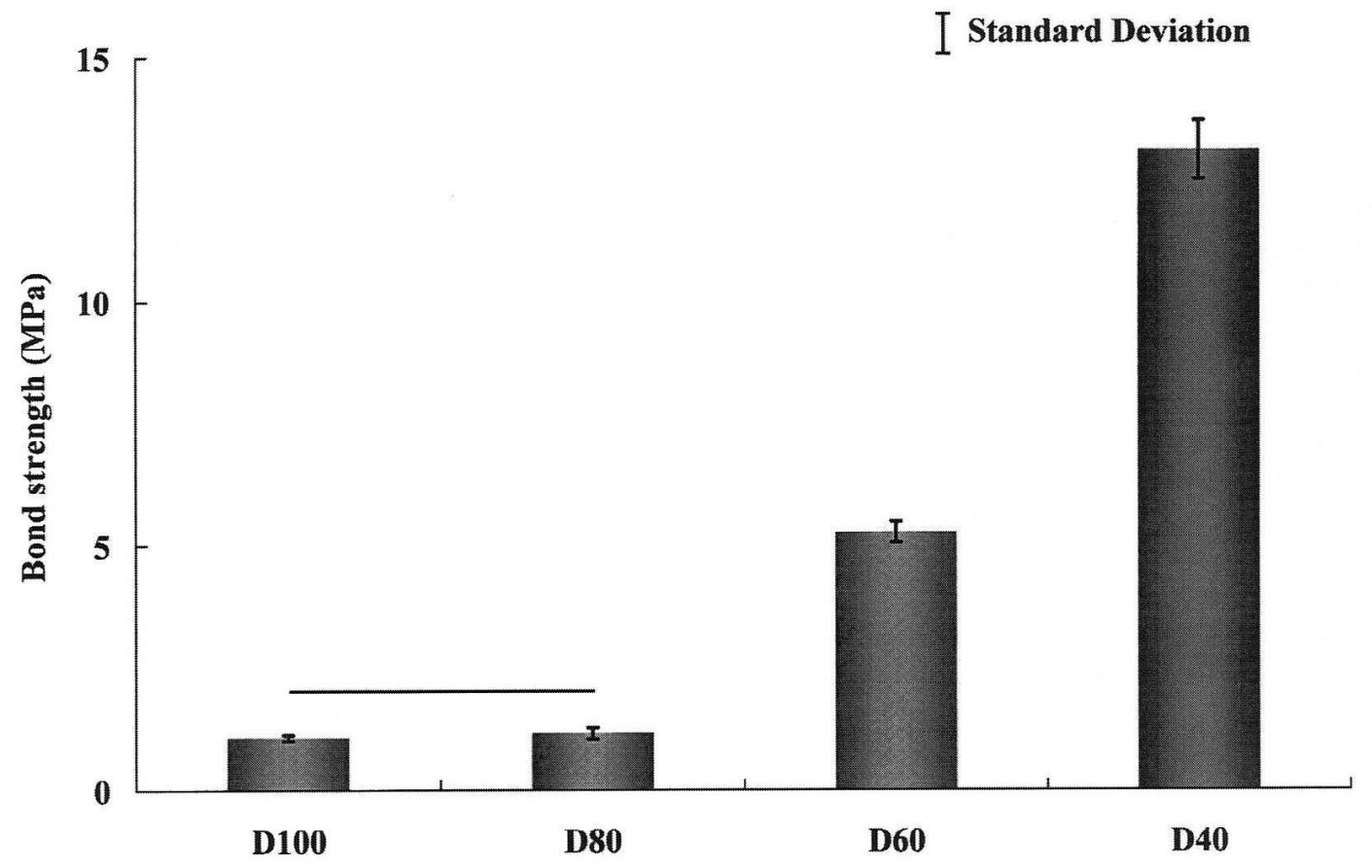

Fig. 2 Tensile bond strength of sample at 0 TC.

Connecting bars indicate no significant difference $(p>0.05)$.

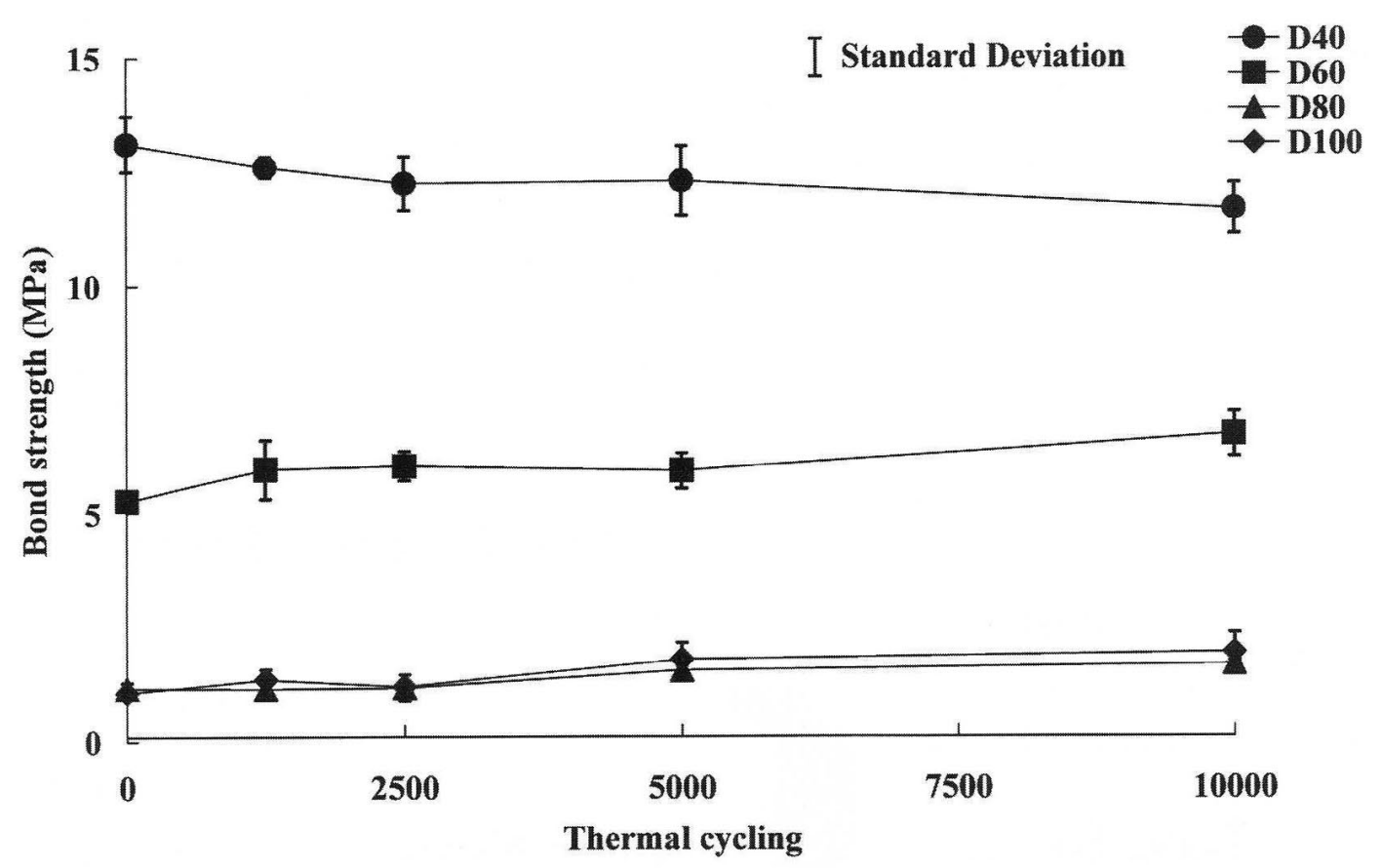

Fig. 3 The influence of the thermal cycling on the tensile bond strength.

force of grip was small. Therefore, the D0 and D20 samples could not be measured. Significant differences $(p<0.05)$ were found among the tensile bond strengths of soft denture liners at 0 TC. The tensile bond strength of the materials to the denture base resin significantly decreased with an increase in plasticizer contents $(\mathrm{p}<0.05)$. Tukey's multiple comparison tests indicated no significant differences between tensile bond strengths of D100 and D80 samples at 0 TC $(p=0.979)$. The D40 sample exhibited significantly higher values of tensile bond strengths (13.1 MPa) than the other materials. The D100 and D80 samples exhibited significantly lower values of tensile bond strengths between soft denture liners 


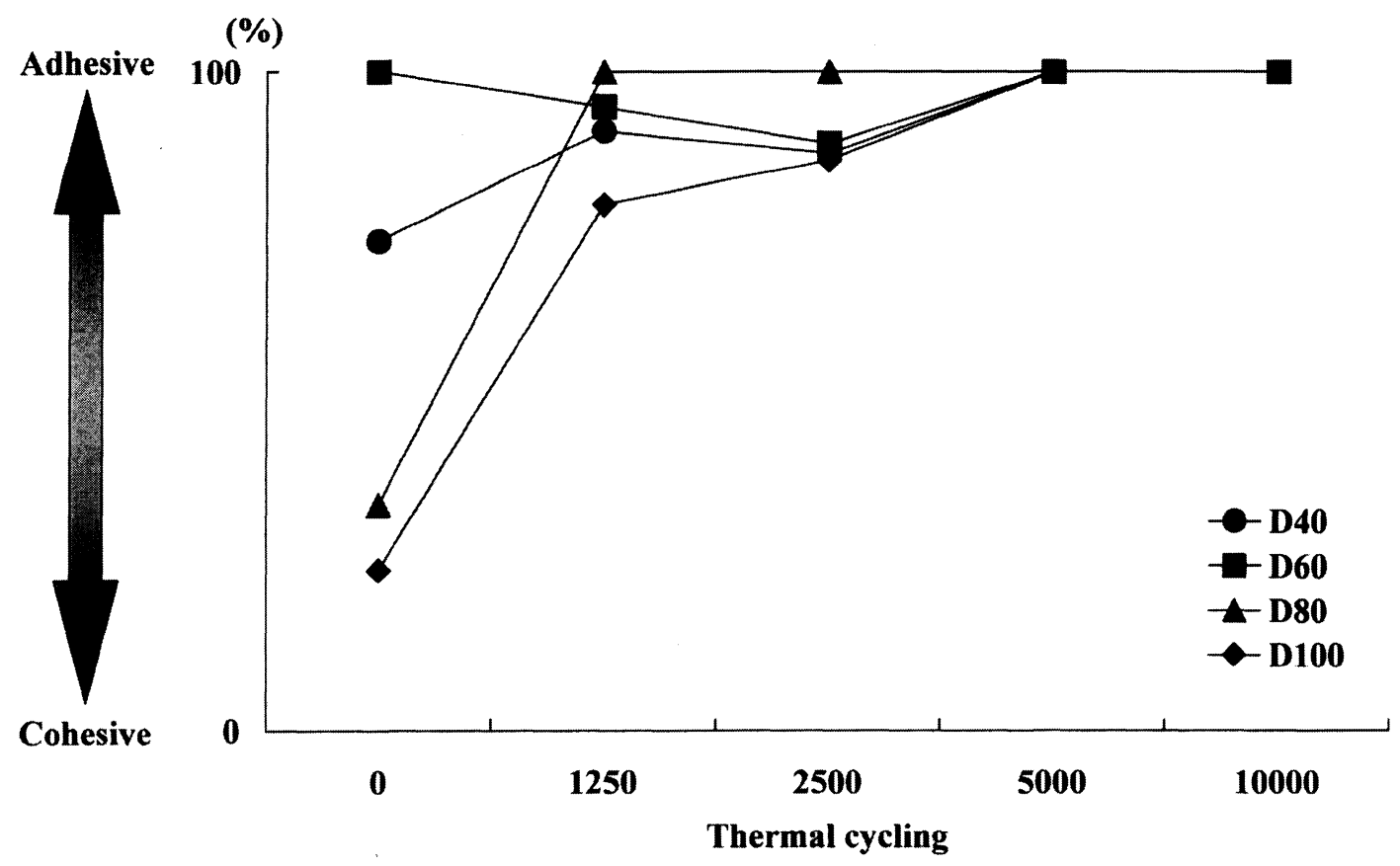

Fig. 4 The influence of the thermal cycling on the failure types.

and denture base acrylic resin $(\mathrm{p}<0.05)$.

The influence of the thermal cycling on the tensile bond strength is shown in Fig. 3. Significant differences were found among the tensile bond strength for the soft denture liners at 1250, 2500, 5000 and 10000 TC $(p<0.05)$. The tensile bond strength of soft denture liners to the denture base resin increased with an increase in thermal cycles significantly $(p<0.05)$, except for D40 samples. The tensile bond strength of D40 samples to the denture base resin significantly decreased with an increase in thermal cycles $(\mathrm{p}<0.05)$. The changes of tensile bond strength values from $0 \mathrm{TC}$ to $10000 \mathrm{TC}$ were as follows: from 1.07 to $1.94 \mathrm{MPa}$ for D100 samples, from 1.17 to $1.68 \mathrm{MPa}$ for D80 samples, from 5.27 to 6.72 $\mathrm{MPa}$ for D60 samples, and from 13.12 to $11.69 \mathrm{MPa}$ for D40 samples.

At 0 TC, most D80 samples showed cohesive failures. Most of the D100 samples showed mixed failures, and D40 samples showed adhesive and cohesive failures at 0 TC. D60 samples showed adhesive failure at 0 TC. The failure types exhibited a tendency for adhesive failure to increase with an increase in thermal cycling (Fig. 4).

\section{DISCUSSION}

Soft denture liners with viscoelastic properties have been a valuable asset for prosthetic clinical use ${ }^{1)}$. Sufficient bond strength between the soft denture liner and acrylic denture base resin is required to avoid interfacial separation during clinical use. This study measured the tensile bond strength between heat-cured acrylic soft denture liners with six different plasticizer contents to a denture base resin, and the influence of the thermal cycling on bond strength between the soft denture liners and denture base resin was also examined.

In this study, we used heat-cured acrylic soft denture liners and heat-cured acrylic resin as a denture base material because the values of bond strength between heat-cured acrylic soft denture liner and denture base resin are larger than those of the other types of materials ${ }^{8)}$.

The estrogenic behaviors of certain phthalates in vivo and in vitro have been reported previously ${ }^{22,23)}$. Hashimoto et al. reported that phthalate esters which were included in various dental materials as plasticizers showed estrogenic activity in vitro ${ }^{24)}$. However, DBS, which is aliphatic ester, is plasticizer used as polyvinylidenechloride film in packing food ${ }^{25)}$. Moreover, DBS was recognized as a safe plasticizer by the American Food and Drug Administration (FDA) because this plasticizer is odor-free and avirulent. Therefore, DBS was used for the liquid component of the soft denture liners as a plasticizer in this study.

The highest tensile bond strength between soft denture liners and denture base acrylic resin was found with D40 samples at 0 TC. Because D40 samples have the highest content of acrylic monomer $(60$ wt\%) compared with the other materials, compatibility with the denture base acrylic resin would be higher and bond strength would become higher ${ }^{15)}$.

The D100 and D80 samples exhibited lower values of tensile bond strengths between soft denture liners 
and denture base acrylic resin. D80 samples contain the acrylic monomer of the $20 \mathrm{wt} \%$, and the D100 samples do not contain the monomer, so compatibility with the acrylic resin for denture plate would be low. Therefore, a lower tensile bond strength would be found.

At the $0 \mathrm{TC}$, most D80 samples showed cohesive failures. This indicates that the tear strength of the soft denture liners is smaller than the bond strength to denture base resin. Most of the D100 samples showed mixed failures at $0 \mathrm{TC}$. This means that the bond strength to denture base is close to the tear strength of the liners. The bond strength of D80 and D100 samples to the denture base resin significantly increased with an increase in thermal cycles. The failure types tended to be adhesive failures by increases in thermal cycling. Materials deteriorate due to the dissolution of soluble components such as plasticizer. Therefore, the tear strength of soft denture liners became greater than bond strength to denture base resin. This is the reason why adhesive failure happened. In the preliminary test, the tear strength of the D40 samples and D60 samples were $12.21 \mathrm{MPa}$ and 7.51 MPa, respectively. The D40 samples showed adhesive and cohesive failure at 0 TC. This may indicate that the tear strength of soft denture liners and the bond strength are almost the same. The tensile bond strength of D40 samples to the denture base resin significantly decreased with an increase in thermal cycles. A boncling surface swells due to the absorption of water in to the soft denture liner and stress may increase in the interface with the soft denture liners and the denture base acrylic resin. The water absorption of the material may be promoted by monomer in the liquids. The D60 sample showed adhesive failure at $0{ }^{\mathrm{TC}}$, which implies that the tear strength of the soft denture liners was greater than bond strength to denture base resin.

It has been reported that the tensile bond strength of the commercial acrylic soft denture liners to denture base resin is from 1.0 to $4.0 \mathrm{MPa}^{8,11,17)}$. The results of this study indicate that the force for failure is higher than $0.46 \mathrm{MPa}$ for all soft denture liners tested. It has been reported that 10 pounds per inch $(0.45 \mathrm{MPa})$ would be satisfactory for clinical use of the resilient denture liner materials ${ }^{10,26,27)}$. Considering this criterion, all soft denture liners tested had satisfactory bond strength to denture base resin.

The tensile bond strength between soft denture liners and denture base acrylic resin became lower with an increase in plasticizer contents. Compatibility between soft denture liners and denture base acrylic resin would become lower with a decrease in monomer contents.

Ideally in the clinical setting, the bond strength of soft denture liner to a denture base resin is high. Therefore, we should decrease the plasticizer content.
However, an appropriate amount of plasticizer content is necessary in order to produce effective viscoelasticity as a soft denture liner. Attention should be given because too great a content of plasticizer will produce degradation of the materials.

In this study, from the standpoint of handling, we thought the desirable plasticizer content to be from 40 to $80 \mathrm{wt} \%$. However, the viscoelastic properties are a most important factor in a soft denture liner. Therefore, to develop a soft denture liner which includes DBS, we think that the influence of plasticizer content on the viscoelasticity of soft denture liners, influence of cross-linking agent on the mechanical properties, age changes of viscoelastic properties, the ISO standard test and so on is necessary.

From this result, the tensile bond strength between soft denture liners and the denture base resin was found to be greatly influenced by plasticizer contents. The tensile bond strength of soft denture liners to the denture base resin decreased with an increase in plasticizer contents. From the standpoint of adhesion, a soft denture liner which includes DBS may be developed.

\section{CONCLUSION}

The results of this study are summarized as follows.

1. Significant differences were found among the different plasticizer contents for tensile bond strengths between the denture base resin and soft denture liners.

2. The influence of the thermal cycles on bond strength between soft denture liners and denture base resin varied among the materials.

3. Differences were found among the different plasticizer contents for failure types between the denture base resin and soft denture liners.

The results suggest that the tensile bond strengths between heat-cured acrylic soft denture liners and the denture base resin were lower with an increase in plasticizer content.

\section{ACKNOWLEDGMENT}

This research was supported in part by a Grant-inAid (No.15390593) for Scientific Research from the Ministry of Education, Culture, Sports, Science and Technology, Japan.

\section{REFERENCES}

1) Wright PS. The success and failure of denture softlining materials in clinical use. J Dent 1984; 12: 319327.

2) Murata H, Taguchi N, Hamada T, McCabe JF. Dynamic viscoelastic properties and the age change of long-term soft denture liners. Biomaterials 2000; 21: 
1421-1427.

3) McCabe JF. Soft lining materials: composition and structure. J Oral Rehabil 1974; 3: 273-278.

4) Braden M, Wright PS, Parker S. Soft lining materials. A review. Eur J Prosthodont Rest Dent 1995; 3: 163174.

5) Murata H, Taguchi N, Hamada T, Kawamura M, McCabe JF. Dynamic viscoelasticity of soft liners and masticatory function. J Dent Res 2002; 81: 123-128.

6) Amin WM, Fletcher AM, Ritchie GM. The nature of the interface between polymethyl methacrylate denture base materials and soft lining materials. J Dent 1981; 9: 336-346.

7) Sinobad D, Murphy WM, Huggett R, Brooks S. Bond strength and rupture properties of some soft denture liners. J Oral Rehabil 1992; 19: 151-160.

8) Kutay O. Comparison of tensile and peel bond strengths of soft liners. J Prosthet Dent 1994; 71: 525531.

9) Sauve JL. A clinical evaluation of Silastic 390 as a lining material for dentures. $J$ Prosthet Dent 1966; 16 : 650-660.

10) Khan Z, Martin J, Collard S. Adhesion characteristics of visible light-cured denture base materials bonded to soft lining materials. J Prosthet Dent 1989; 62: 196-200.

11) Kawano F, Dootz ER, Koran III A, Craig RG. Bond strength of six soft denture liners processed against polymerized and unpolymerized poly (methyl methacrylate). Int J Prosth 1997; 10: 178-182.

12) Wright PS. Characterization of the adhesion of soft lining materials to poly (methyl methacrylate). J Dent Res 1982; 61: 1002-1005.

13) Kulak-Ozkan Y, Sertgoz A, Gedik H. Effect of thermocycling on tensile bond strength of six siliconebased, soft denture liners. J Prosthet Dent 2003; 89: 303-310.

14) Al-Athel MS, Jagger RG. Effect of test method on the bond strength of a silicone soft denture lining material. J Prosthet Dent 1996; 76: 535-540.

15) Wright PS. Composition and properties of soft lining materials for acrylic dentures. J Dent 1981; 9: 210-223.

16) Polyzois GL. Adhesion properties of soft lining materials bonded to light-cured denture resins. J Prosthet
Dent 1992; 68: 854-858.

17) Emmer Jr TJ, Emmer Sr TJ, Vaidynathan J, Vaidynathan TK. Bond strength of permanent soft denture liners bonded to the denture base. J Prosthet Dent 1995; 74: 595-601.

18) Al-Athel MS, Jagger RG. Bond strength of soft lining materials to various denture base resins. Int $J$ Prosth 1996; 9: 167-170.

19) Aydın AK, Terzioğlu H, Akınay AE, Ulubayram K, Hasircı N. Bond strength and failure analysis of lining materials to denture resin. Dent Mater 1999; 15: 211218.

20) Takahashi Y, Chai J. Assessment of shear bond strength between three denture reline materials and a denture base acrylic resin. Int J Prosth 2001; 14: 531535 .

21) McCabe JF, Carrick TE, Kamohara H. Adhesive bond strength and compliance for denture soft lining materials. Biomaterials 2002; 23: 1347-1352.

22) vom Saal FS, Cooke PS, Buchanan DL, Palanza P, Thayer KA, Nagel SC, Parmigiani S, Welshons WV. A physiologically based approach to the study of bisphenol and other estrogenic chemicals on the size of reproductive organs, Daily sperm production and behavior. Toxicol Ind Health 1998; 14: 239-260.

23) Perez P, Pulgar R, Olea-Serrano F, Villalobos M, Rivas A, Metzler M, Pedraza V, Olea N. The estrogenicity of bisphenol A-related diphenylalkanes with various substituents at the central carbon and the hydroxy groups. EHP 1998; 106: 167-174.

24) Hashimoto $Y$, Kawaguchi M, Miyazaki K, Nakamura M. Estrogenic activity of tissue conditioners in vitro. Dent Mater 2003; 19: 341-346.

25) Castle L, Mercer AJ, Startin JR, Gilbert J. Migration from plasticized films into food 3. Migration of phthalate, sebacate, citrate and phsphate esters from films used for retail food packing. Food Addit Contam 1988; 5: 9-20.

26) Craig RG, Gibbons P. Properties of resilient denture liners. J Am Dent Assoc 1961; 63, 382-390.

27) Eick JD, Craig RG, Peyton FA. Properties of resilient denture liners in simulated mouth conditions. J Prosthet Dent 1962; 12, 1043-1052. 